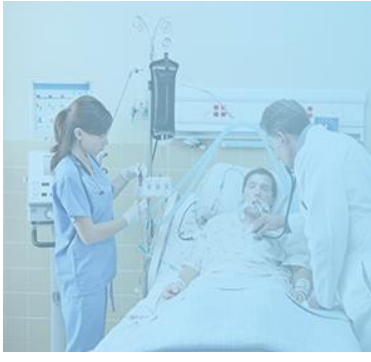

E-ISSN: $2663-2268$

P-ISSN: 2663-225X

IJARMSN 2020; 2(1): 19-22

Received: 11-11-2019

Accepted: 14-12-2019

Christiana Asiedu

Ph.D., Department of Adult Health, School of Nursing and Midwifery, College of Health and Allied Sciences, University of Cape Coast, Ghana

Francis Adu-Donyina Boahen BHS, RGN, Department of Science Education, University of Cape Coast, Ghana
Corresponding Author: Christiana Asiedu Ph.D., Department of Adult Health, School of Nursing and Midwifery, College of Health and Allied Sciences, University of Cape Coast, Ghana

\section{Challenges of learning and implementation of nursing process among students at psychiatry nursing training school at ankaful in the central region of Ghana}

\author{
Christiana Asiedu and Francis Adu-Donyina Boahen
}

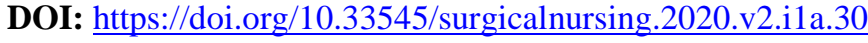

\begin{abstract}
Introduction: Nursing process serve as a guide for nurses to efficiently care for patients through scientific process.

Aim: To find out some of the challenges associated with the learning and implementation of nursing process among student nurses.

Methods: This study was quantitative with descriptive research design. Participants were nursing students between the ages 18-32 in level 100, $200 \& 300$. Multi stage sampling technique was used to sample 215 respondents. Questionnaire was used to collect the data. Analyses of data were done using descriptive statistics.

Results: The respondents had good basic knowledge about the nursing process. It was found out that, the time consumption involved in its use, difficulty with diagnosis and its complicated nature were some difficulties in the learning and implementation of the nursing process.

Conclusion: The nursing process should be taught as a course on its own other than a topic.
\end{abstract}

Keywords: Challenges, implementation, nursing process, nurses, professionals

\section{Introduction}

The idea of the nursing process was borrowed from the General System Theory (GST) by the North American Nursing Profession and it developed gradually as professional nurses decided to document the care being rendered to patients. Nursing process serve as a guide for nurses to efficiently care for patients through scientific reasoning, problem solving and deductive thinking (Yildirim, \& Özkahraman, 2011) ${ }^{[13]}$. The technological advancement in the health care system calls for the proper utilisation of the nursing process as it brings on board quality care, alleviates suffering and promotes speedy recovery. With the nursing process, the nurse collaborates with the patient in providing care, upholding confidentiality and enhancing coping mechanisms to stress (Donkor, 2009) ${ }^{[7]}$. The sad reality about the nursing process is that its implementation in the various hospitals falls below what is actually expected). There seems to be a gap between the knowledge gained in the nursing process and its corresponding level of application in Ghanaian health facilities. Many nurses are knowledgeable but, implement very little thereby putting the patient's health in jeopardy (Enfermagem, 2009) ${ }^{[8]}$.

The gap that exist between knowledge acquired and its implementation can be attributed to two main causes. First of all the nursing process seems realistic in theoretical bases than in practice. The next possible problem is that even when the theory is practical and beneficial to patients, some nurses do not act on it, possibly due to inadequate knowledge or the inadaptable settings in which they work or because they intentionally overlook it (Brake, 2005) ${ }^{[5]}$. Many student nurses do not value the nursing process and this has led to poor patient care and outcome. Despite structured and comprehensive training of student nurses, gaining knowledge in various nursing training institutions and various hospitals in the country on nursing process, evaluation reports at the hospitals shows an evidence of low implementation of nursing process among nurses (Donkor, 2009) ${ }^{[7]}$. Hence this study seeks to find the challenges Students nurses face in the learning and implementation of the nursing process. 


\section{Specific objectives}

1. To assess the knowledge students, have on nursing process and its application

2. To determine factors hindering the learning and implementation of nursing process.

\section{Methodology}

Research design

A cross-sectional descriptive method was used for this study and it employed quantitative technique for data collection.

\section{Study area}

The study was conducted in the Central region. Central Region is one of the sixteen regions of Ghana and it shares boundaries with Ashanti and Eastern region to the north and western region to the west and the Gulf of Guinea to the south.

\section{Population}

Four hundred and eighty student nurses constituted the population for the study. They were within the ages 18-32 in level 100, $200 \& 300$ respectively.

\section{Sampling Procedure}

The sample size for the study was 215 (determined from Krejcie and Morgan table) and was made up of 182 first year, 159 second year and 139 third year nursing students. The sample size for each level was determined from the class population using ratio and proportion. Multi stage sampling was used in selecting the respondent.

Calculation of sample of each class 182:159:139=215

$$
\text { Example for first years } \frac{182}{480} \times 215=82
$$

\section{Data collection Instrument}

A structured questionnaire was used to collect data from the respondents and was organised into five major sections. Section (A) sought to elicit demographic information about the respondents. Questions covered variables such as gender, age, level, program pursuing, religion, marital status, and previous occupation. This section gave a fair idea about the respondents and also aided in grouping of data for analysis of results. Section (B) asked questions on knowledge of the nursing process. Section (C) focused on factors hindering the learning and implementation of the nursing process.

\section{Data collection procedures}

Before the data collection, permission was sought from authorities to carry out the study. The data collection was conducted by the researcher on $3^{\text {rd }}$ May, 2019. The purpose of the study was explained to the respondents. The questionnaire were then given to the selected students. After filling, the copies were collected on the spot.

\section{Data processing and analysis}

The data collected was edited to correct errors, check for non-responses, and accuracy. Coding was done to facilitate a comprehensive analysis of the data. During coding items in the Likert scale, positive worded statements were coded as 1 for Strongly Disagree (SD), 2 for Disagree (D), 3 for Agree (A) and 4 for Strongly Agree (SA) respectively. For negative worded statements, coding was done as 1 for Strongly Agree, 2 for Agree, 3 for Disagree and 4 for Strongly Disagree respectively. To arrive at the intended analyses, the participants' responses were keyed into Statistical Package for Social Sciences (SPSS) version 22.0. The researcher minimised errors by checking whether data entered corresponded to that of the respondents. Descriptive statistics were used to analyse all the four research objectives and tables were used to clarify data that were presented.

\section{Results}

The data presented in Table 1 shows the general characteristics of the Study participants. Most of the respondents, $52.6 \%$ (113) were males and $75.8 \%$ (163) were in the age range of 21-25 years. Again, the data shows that majority, $87.4 \%$ (188) of the respondents were pursuing the Registered Mental Nurse programme. The first-year students of the college formed the majority of the respondents with $38.1 \%$ (82. Many of the respondents, 91.6\% (197), reported to be Christians. Lastly, the marital status information shows that a greater number of the respondents, $94.4 \%$ (203) were single.

From the data presented in Table 2,61.9\% (133) indicating a majority of the respondents, strongly agreed to the statement that the nursing process permits the prioritised individualisation of care. Again, the data shows that most of the respondents, $54.4 \%$ (117), strongly disagreed to the claim that the nursing process is a mean of unifying nursing practice. It was also observed from the table that, a greater percentage of the participants, $57.7 \%$ (124), strongly disagreed that the nursing process is only used for patients in critical conditions. When posed to the statement that the nursing process allows a review and evaluation of nursing interventions, $57.7 \%$ (124) representing the majority of the respondents, strongly agreed. Lastly, in responding to the claim that the nursing process is a planned activity of medical doctors, many of the respondents, $49.8 \%$ (107), strongly disagreed.

From table 3, the data shows that most of the participants, $44.7 \%$ (96) agreed that they come across staff nurses who use the nursing process to care for patients on the ward. Again, a majority, $41.9 \%$ (90), of the participants agreed that they get supervised to use the nursing process on the wards, indicating that, most student nurses on clinical practice are supervised to use the nursing process in caring for patients. Also, a greater percentage of the respondents, $37.2 \%$ (80), agreed that they see care plan sheets in the hospitals they visit. Moreover, many of them, $41.4 \%$ (89) forming the majority, agreed that nursing process was taught to be used in practical terms. Again, 49.8\% (107) agreed that they can practice nursing process competently with the training they had acquired. However, majority of the participants, $56.3 \%$ (121), strongly agreed that they still need more tutorials on the nursing process. When given the opportunity to provide additional information on what their difficulties in the learning of the nursing process was, the major concerns raised were that the nursing process is complicated and needs more time to be understood, the concept of nursing process was not well taught and that it is difficult to perform diagnosis of the situation at hand. Also, they indicated that, what hindered them from using the nursing process to care for patients on the ward were; staff on the ward not using the nursing process and as a result not 
encouraging the student nurses to use it, and the high time consumption involved in using the nursing process to care for patients.

\section{Discussion}

The responses provided by the participants in this study portray an image of the student nurses being knowledgeable about the nursing process. Obviously, the nursing process gives the nurse that opportunity to focus on the treatment care of an individual and follow every detail of the patient's condition. The data made available by this study pertaining to the knowledge of nursing students about the nursing process contradict with a qualitative study in Ethiopia which found that nurses had no adequate knowledge to implement the nursing process (Hagos, Alemseged, Balcha, Berche \& Aregay, 2014) ${ }^{[10]}$. The contradiction could be as a result of students' characteristics and the importance each set of the participants for these two studies attached to the nursing process when it was been taught in college. However, this finding does not seem to report that the student nurses' knowledge about the nursing process translates into an effective practice of the nursing process.

With respect to identification of patients' priority being easy using nursing process, the finding of this study is in line with a study in 2007 which claimed that assessment process involved in the nursing process is crucial for nurses to notice special areas that are important, such as identifying certain behaviours and predicting what will happen in the future (Chabeli, 2007) ${ }^{[6]}$. This indicates that when nurses follow the care plan, they are able to identify the priority needs of the patients very easily. Coming across staff nurses who use the nursing process in caring for patients serves as a motivation for student nurses to also do same. As a result, when a student nurse usually sees the staff nurses following that protocol, they learn and do same. As reported that lack of role model among senior nurses is among the factors that militate against nursing care implementation, this study found a contrary view that student nurses see staff nurses using the nursing process (Laryea, 2004) ${ }^{[11]}$. This might be due to an increased sensitization for the use of the nursing process among staff nurses.

The nursing process cannot be fully and effectively implemented if the requisite resources and supplies are not provided. Especially, when human resource capacity is low, the nurse to patient ratio increases and the nurses have to do more work than required. Also, lack of requisite supplies such as care plan sheets can frustrate the process. These factors then hinder the implementation of the nursing process (Akbari \& Shamsi, 2011; Garba, Emmanuela, Gimba, \& Afuwai, 2011) ${ }^{[2,9]}$. On the contrary, this study has found, as reported by the respondents, that they see care plan sheets in the hospitals they visit. Issues of logistics might therefore not be a reason for the hindrance of the nursing process, rather human resource may be a factor.

Training is an important factor in the profession of any individual. No individual can become a professional in a field or career without receiving some form of training. Therefore, to increase competence of professionals, training must be adequately done. In this study, majority of the students agreeing to the statement that they can practice the nursing process competently with the training they have had, buttresses the assertion that lack of training affect the application of the nursing process (Alfaro-LeFevre, 2010; Onyemenam, 2013) ${ }^{[3,12]}$. The responses of the majority of the student nurses that they still need more tutorials on nursing process aside classroom teaching conforms to the argument that nurses need to be equipped with knowledge through in-service training and continuous professional development programmes to help improve the implementation of the nursing process (Abebe \& Abera, 2014; Onyemenam, 2013) ${ }^{[12]}$. Often, classroom teaching tends to focus more on theoretical aspects than practical. It was therefore expected that the student nurses would need some form of additional tutoring aside what they have been taught in the classroom. Hence this response was well anticipated.

The finding of this study on the need to get clinical preceptors to supervise the use of the nursing process by all health care professionals also conforms to the assertion that nurses need to be supervised on effective implementation of the nursing process (Bastable, 2008; Onyemenam, 2013) ${ }^{[4,}$ ${ }^{12]}$. This similarity might be possible because humans, by nature, will tend to ignore certain responsibilities unless they are being monitored by some authorised people. It is assumed that workers live up to task when they are under effective supervision. Therefore, this might have accounted for the responses of the student nurses.

Again, it is believed that when the nursing process is made a course on its own rather than being a topic, it will provide the opportunity for both tutors and student nurses to get much time to learn the nursing process very well. Being a course of study makes it broader and students will have to learn wide on it. This will help broaden the knowledge base of the students about the concept.

Table 1: Demographic data of respondents

\begin{tabular}{|c|c|c|}
\hline Variable & Frequency & Percentage \\
\hline Gender & & \\
\hline Male & 113 & 52.6 \\
\hline Female & 102 & 47.4 \\
\hline Age & & \\
\hline 20 or less & 31 & 14.4 \\
\hline $21-25$ & 163 & 75.8 \\
\hline $26-30$ & 16 & 7.4 \\
\hline 30 and above & 5 & 2.3 \\
\hline Programme & & \\
\hline RMN & 188 & 87.4 \\
\hline CPN & 27 & 12.6 \\
\hline Level & & \\
\hline First & 82 & 38.1 \\
\hline Second & 71 & 33.0 \\
\hline Third & 62 & 28.8 \\
\hline Religious Affiliation & & \\
\hline Christian & 197 & 91.6 \\
\hline Islam & 16 & 7.4 \\
\hline Traditional & 2 & 0.9 \\
\hline Marital Status & & \\
\hline Single & 203 & 94.4 \\
\hline Married & 11 & 5.1 \\
\hline Widowed & 1 & 0.5 \\
\hline
\end{tabular}

Source: Field Data (2019) 
Table 2: Respondents' Knowledge on Nursing Process

\begin{tabular}{|c|c|c|c|c|}
\hline Variable & \multicolumn{3}{|c|}{ Frequency (Percentage) } \\
\hline & SD & D & A & SA \\
\hline Nursing Process permits the prioritised individualisation of care. & $74(34.4)$ & $7(3.3)$ & $1(0.5)$ & $133(61.9)$ \\
\hline Nursing Process is a mean of unifying nursing practice. & $117(54.4)$ & $18(8.4)$ & $5(2.3)$ & $75(34.9)$ \\
\hline Nursing Process is only used for patients in critical conditions. & $124(57.7)$ & $16(7.4)$ & $75(34.9)$ & $0(0.0)$ \\
\hline It allows review and evaluation of nursing interventions. & $87(40.5)$ & $2(0.9)$ & $2(0.9)$ & $124(57.7)$ \\
\hline Nursing Process is a planned activity of medical doctors. & $107(49.8)$ & $28(13.0)$ & $80(37.2)$ & $0(0.0)$ \\
\hline
\end{tabular}

Source: Field Data (2019)

Table 3: Factors hindering the Learning and Implementation of Nursing Process

\begin{tabular}{|c|c|c|c|c|}
\hline Variable & \multicolumn{3}{|c|}{ Frequency (Percentage) } \\
\hline SD & D & A & SA \\
\hline I encounter staff nurses who use Nursing Process to care for patients on the ward. & $29(13.5)$ & $40(18.6)$ & $96(44.7)$ & $50(23.3)$ \\
\hline I get supervised to use the nursing process on the wards & $26(12.1)$ & $66(30.7)$ & $90(41.9)$ & $33(15.3)$ \\
\hline I see care plan sheets in the hospital I visit. & $29(13.5)$ & $44(20.5)$ & $80(37.2)$ & $62(28.8)$ \\
\hline The school teaches nursing process to be used in practical terms. & $12(5.6)$ & $25(11.6)$ & $89(41.4)$ & $89(41.4)$ \\
\hline I can practice nursing process competently with the training I have acquired. & $10(4.7)$ & $22(10.2)$ & $107(49.8)$ & $76(35.3)$ \\
\hline I still need more tutorial on nursing process aside the classroom teaching. & $4(1.9)$ & $9(4.2)$ & $81(37.7)$ & $121(56.3)$ \\
\hline
\end{tabular}

Source: Field Data (2019)

\section{Conclusions}

It can be concluded based on the findings of this study that the student nurses in the study area had basic knowledge and positive perceptions about the nursing process. The major factors that hinder the implementation of the nursing process among student nurses are the time involved in its use and the lack of encouragement or support from staff nurses. Once the student nurses have that notion that it is time consuming to use the nursing process, they tend not to engage it in their practice. This hindrance can be managed if the nurse to patient ratio is reduced enough to lay off pressure on the nurses. This can be achieved by making it a course on its own rather than teaching it as a topic.

\section{References}

1. Abebe N, Abera $\mathrm{H}$. The implementation of Nursing process and Associated Factor among Nurses working in Debremarkos and Finotese I am Hospitals. North West Ethiopia. Journal of nursing and Care. 2014; 3(149):11-68.

2. Akbari M, Shamsi A. A survey on nursing process barriers from the nurses' view of intensive care units. Iranian Journal of Critical Care Nursing. 2011; 4(3):181-186.

3. Alfaro-LeFevre R. Applying nursing process: A tool for critical thinking (7th ed). Lippincott, Philadelphia: Williams \& Wilkins, 2010.

4. Bastable SB. Nurse as Educator: Principles of teaching and learning for nursing practice $\left(3^{\text {rd }}\right.$ ed.). Ontario: Jones and Bartlett Publishers, 2008.

5. Brake J. Bridging the gap between knowledge and practice. Journal of diabetes nursing, 2005; 9(3):92-96.

6. Chabeli MM. Facilitating critical thinking within the nursing process framework: a literature review. Health SA Gesondheid. 2007; 12(4):69-89.

7. Donkor N. Challenges and Opportunities of the $21 \mathrm{st}$ Century Nursing Practice in Ghana. A paper presented at the International Conference of Nursing, Accra, Ghana, 2009.

8. Enfermagem L. Nursing process: from literature to practice. What are we actually doing? Maio-junho, 2009; 17(3):302-307.

9. Garba SN, Afoi BB, Emmanueul A, Gimba SM,
Afuwai V. Evaluation of the implementation of nursing process among nurse clinicians. Continental journal of Nursing Science. 2011; 4(1):34-46.

10. Hagos F, Alemseged F, Balcha F, Berhe S, Aregay A. Application of Nursing Process and Its Affecting Factors among Nurses Working in Mekelle Zone Hospitals, Northern Ethiopia. Nursing Research and Practice, 2014, 1-9.

11. Laryea J. Barriers to implementation of the nursing process. West African College of nursing journal. 2004; 5(3):10-17.

12. Onyemenam T. Factors that hinder the implementation of Nursing Process (Case study: matter Misericordiae Hosp. Afikpo, Ebongi State) nursing research and practice, 2013; 2(13):4-11.

13. Yildirim B, Özkahraman S. Critical thinking in Nursing process and education. International Journal of Humanities and Social Science, 2011. 